\title{
Assessment of urban development policies in the context of sustainability in Latvia
}

\author{
A. Zilans \\ Faculty of Geography and Earth Sciences University of Latvia, Latvia
}

\begin{abstract}
An assessment of the sustainability of urban development policies was undertaken in six major cities in Latvia using a methodology developed as part of the Aalborg Commitments baseline review for the city of Riga. Development planning documents and development indicators and trends were assessed against the Aalborg Commitments. The assessment revealed significant discrepancies between the sustainability criteria of the Aalborg Commitments and development policy goals and measures defined in the municipal planning documents. Development goals provide cities with a weak orientation towards sustainability, whereas policy measures show limited coherence with development goals and the Aalborg Commitments. None of the strategic development plans of the investigated cities reflect all the Aalborg Commitments and none reflect issues in the group Local to Global. Only three of the cities studied have a limited number of sustainability indicators that can be used in part to measure progress towards sustainable development. Based on the available indicators development in these cities is characterized by predominantly unsustainable trends. The results of a survey of municipal administration personnel and council deputies indicate that deficiencies in governance, including knowledge about sustainable development, policy integration, intersector cooperation, municipality and stakeholder cooperation and urban management contribute to development policies and outcomes that are weakly supportive of sustainable development and act as barriers to mainstreaming sustainable development.
\end{abstract}

Keywords: Aalborg Commitments, governance, indicators, intersector cooperation, policy integration, sustainability criteria, sustainable development, urban development policies. 


\section{Introduction}

The authoritative report "Our Common Future" written by the World Commission on Environment and Development [1], commonly known as the Brundtland Report, for the first time raised the concept and goal of sustainable development onto the global political agenda. The Brundtland Report and the subsequent Agenda 21 adopted at the United Nations Conference on Environment and Development (UNCED) held in Rio de Janeiro in 1992 [2] was the catalyst for global activities by all levels of government and by nongovernmental organizations, the private sector and the scientific community to better understand the implications of the new sustainable development paradigm and to begin the uncertain task of operationalizing it in practice.

The goal of sustainable development is included in the European Union's Lisbon Strategy and has been reiterated in the Renewed EU Sustainable Development Strategy [3]. The Renewed EU Sustainable Development Strategy encourages municipalities, cities and towns to sign and implement the Aalborg Commitments - criteria and a framework for fostering sustainable development at the municipal level. Similarly, the Thematic Strategy on the Urban Environment [4] sets out to support Members state and local authorities by promoting Europe's best practice on the urban environment, facilitating the widespread use of best practice throughout Europe, encouraging effective networking and exchange of experience between cities. The Europe 2020 strategy focuses on delivering smart, sustainable and inclusive growth in the European Union. Sustainable growth is defined in relation to building a more competitive low-carbon economy that makes efficient, sustainable use of resources and in terms of protecting the environment, reducing emissions and preventing biodiversity loss [5].

Latvia is bound by these international and EU commitments to sustainable development and at the national level in Latvia sustainable development is defined as a political objective [6], however progress towards sustainability has largely been declarative, not in practical measures and outcomes. According to Latvian planning law, municipal development planning strategies, plans, programmes and land use plans are the main instruments for guiding development at the local municipal level and should adhere to the principle of sustainable development "development that ensures present and future generations with a quality environment, balanced economic development, rational use of natural, human and material resources and development and preservation of natural and cultural heritage" [7, 8]. Since sustainable development is a general idea that must be adapted to specific local social, cultural and political conditions monitoring the orientation of development policies and trends in relation to sustainable development is highly relevant to ensure desired outcomes. This paper presents the results of an assessment of the development policies and development indicators in six national level cities (Riga, Daugavpils, Liepaja, Jurmala, Ventspils, Rezekne) in Latvia against the sustainability criteria of the Aalborg Commitments and the results of a survey of 
municipal personnel and council deputies regarding municipal institutional arrangements and governance practices in the context of sustainability.

\subsection{Characterization of sustainable development}

Sustainable development in Agenda 21 [9] was described as three dimensions, the social, economic and environmental and a process of bringing these development processes into balance with each other. Although the institutional dimension of sustainability was not explicitly defined, institutions as a tool for its implementation were attributed a central role in sustainable development. Apart from Chapters 8 and 38 of Agenda 21 that directly focus on institutional aspects of sustainable development, all other chapters assign clear tasks to institutions [10]. The institutional dimension was made explicit in the system of indicators developed by the United Nations Commission on Sustainable Development [11] - formal and non-formal institutions and related practices and processes that structure social behaviour in various contexts [12].

As sustainable development requires many factors to be taken into consideration, a horizontal multi-criteria approach is required [13, 14]. Furthermore, due to the non-linear character of environmental, economic, social and human dynamics any long-term predictions regarding the results of specific policy measures are of only limited reliability. Consequently, sustainable development needs to be considered an iterative process with a broadly based participatory governance to keep it on track. Top-down management of a set of interlinked complex non-linear systems, according to an integrated, multipurpose set of targets is not entirely feasible. Direct steering of sustainability politics must be complemented and partly replaced by indirect management. The focus is shifted towards setting the right framework conditions using criteria to activate the inherent dynamics and self-organization capabilities and give them direction towards sustainability [15].

\subsection{The Aalborg process and commitments}

Chapter 28 of Agenda 21 recognized the important role local municipalities play with regards to environmental and sustainable development issues and spurred Local Agenda 21 related activities worldwide. Within this context, in 1994, in Aalborg, Denmark, the International Council for Local Environmental Initiatives (ICLEI) launched the European Sustainable Cities \& Towns Campaign and its centrepiece the "Aalborg Charter" - a framework of sustainable development principles for European cities and towns [16]. Over the next ten years more than 2000 municipalities in 34 countries signed the Aalborg Charter and undertook to develop a Local Agenda 21 through a process of consultations with community stakeholders and to plan urban development on the basis of sustainability principles. In Latvia, the Aalborg Charter was signed by the capital city Riga, Jurmala, Jekabpils, Bartava municipal association and Tukums (provisional).

In 2004, the Aalborg Commitments initiative was launched to strengthen efforts towards urban sustainability in Europe [17]. The Aalborg Commitments are criteria and conditions that cities and towns can voluntarily undertake in 
order to to translate a common vision of sustainable development into tangible sustainability targets and actions at the local level. At the heart of the Aalborg Commitments are 50 sustainability criteria, consisting of ten topical groups each containing five sustainability criteria, which can serve as guidelines for the planning, implementation and evaluation of sustainable urban development. The first ten are criteria for the sustainability implementation process: criteria for a participatory, open, transparent and accountable form of governance (criteria 15) and criteria for developing a systematic and iterative approach towards sustainability using management tools (criteria 6-10). Criteria 11-50 define the "content" or specific objectives of the economic, social and environmental dimensions of sustainability. Together the Aalborg Commitment criteria form a framework "to activate the inherent dynamics and self-organization capabilities in society and give them direction towards sustainability" [15].

\section{Study methods and methodology}

An assessment was undertaken of the development policies and development trends in six national level cities (Riga - pop. 699200, Daugavpils - pop. 101000, Liepaja - pop. 82400, Jurmala - pop. 56300 , Ventspils - pop. 38600 , Rezekne - pop. 32200) in Latvia against the sustainability criteria of the Aalborg Commitments using a methodology initially developed as part of the Aalborg Commitments baseline review for the city of Riga [18]. The methodology was further tested and refined in the context of a sustainability assessment of development policies in the Latvian town of Cesis [19].

At the basis of the methodology is an assessment of municipal planning documents against the Aalborg Commitments at two levels. Firstly, the policy goals defined in development planning documents (strategic plans and sector plans) were analysed against the Aalborg criteria. Similarly, policy measures defined in these development planning documents were analysed. All of the aforementioned analyses were undertaken on a three point scale:

1 - represented;

2 - partially represented;

3 - not reflected.

The category "represented" indicates full and unambiguous definition of an Aalborg Commitments criterion by a policy goal and policy measure. "Partially represented" indicates that an Aalborg Commitment criterion is only in part represented as a policy goal or policy measure, or the formulation in the development planning document(s) is ambiguous, or it is contradictory within the same plan or between plans. "Not reflected" means that the specific Aalborg Commitment criterion is not reflected in the policy goals and/or measures of the development planning document. The analysis was undertaken to identify which Aalborg Commitments have been formulated explicitly as policy goals in municipal planning documents and whether these goals have been further elaborated as specific measures or actions that are harmonized with defined policy goals. The intended output is a measure of the strength and coherence of municipal sustainability policy in the framework of the Aalborg Commitments. 
Indicators used to monitor development in the six cities were analysed for their adequacy to monitor sustainable development within the Aalborg Commitments framework. Using a three point scale, an assessment was undertaken of the availability of appropriate indicators to monitor the implementation of the Aalborg Commitments:

1 - appropriate indicators exist;

2 - partially appropriate indicators exist;

3 - appropriate indicators do not exist.

For those Aalborg Commitments for which appropriate or partially appropriate indicators exist, development trends were characterized using the following classification system:

1 - Development trends are consistent with the Aalborg Commitments;

2 - Development trends are partially consistent with the Aalborg Commitments;

3 - Development trends are contradictory to the Aalborg Commitments;

4 - Development trends are not known because there are no indicators or data.

The analysis was intended to identify gaps in indicators and data requirements for monitoring the implementation of the Aalborg Commitments.

In order to assess institutional arrangements and governance practices in the six cities, municipal council deputies and municipal administration personnel were surveyed using written questionnaires. Separate, but similar questionnaires were used for each of the target groups. The questionnaires contained both open and closed questions. The number of questions in the two questionnaires and the response rates were as follows:

Municipal council deputies: 18 questions; 29 respondents (Riga -10 , Daugavpils - 2, Liepaja - 3, Jurmala - 0, Ventspils - 5, Rezekne 9).Municipal administration personnel: 27 questions; 77 respondents (Riga - 44, Daugavpils - 3, Liepaja - 15, Jurmala - 5, Ventspils - 3, Rezekne -7 .

\section{Results of the assessment}

\subsection{Results of the assessment development and sector plans}

The spider-net diagrams in figures 1-6 summarize the assessment of strategic development plan and sector plan policy goals and measures against the sustainability criteria of the Aalborg Commitments in the six cities studied. The assessment reveals that a large number of Aalborg Commitments are not reflected in the policy goals of the strategic development and sector plans indicating that the policy goals defined therein provide these cities with a weak orientation towards sustainability. Policy measures defined in these plans show a significantly lower coherence with the Aalborg Commitments. Frequently, both in the strategic development plan and sector plan policy measures are in contradiction to defined policy goals. The overall weak coherence of policy goals and measures with the Aalborg Commitments indicates a lack of strategic direction towards sustainable development. This weak coherence is evidenced also by Riga which is a signatory of the Aalborg Charter and Commitments. 
The strategic development plans in the six cities show a significantly differing coherence with the Aalborg Commitments indicating that development priorities differ. None of the cities have strategic development plans that reflect all of the Aalborg Commitments and none reflect any of the issues in Aalborg Commitment group 10 - Local to Global indicating that development planning at the local level is not being linked to global processes. All of the strategic development plans analysed have policy goals that are at least partially coherent with Aalborg Commitments groups 3 - Natural Common Goods, 8 - Vibrant and Sustainable Local Economy and 9 - Social Equity and Justice reflecting the priority issues for most Latvian municipalities - economic development and employment, communal services, social exclusion and nature protection.

The policy measures defined in all of the analysed strategic development plans show a significantly lower coherence with the Aalborg Commitments. This can be partly explained by the function of strategic development plans which is primarily the formulation of development goals which can be worked towards by developing sector plans with appropriate policy measures or actions. Only in the case of Daugavpils, where there is a close correspondence between the policy goals in the strategic plans and the goals and measures in the sector plans, is it evident that development planning is undertaken in a systematic and coordinated fashion.

Overall the strategic development plans of Riga (figure 1) and Rezekne (figure 6) show the best, although incomplete, coherence with the Aalborg Commitments. The strategic development plans of Daugavpils (figure 2) and Jurmala (figure 4) show a lower coherence with the Aalborg Commitments, whereas, overall, the strategic plans of Liepaja (figure 3) and Ventspils (figure 5) show weak coherence with the Aalborg Commitments.

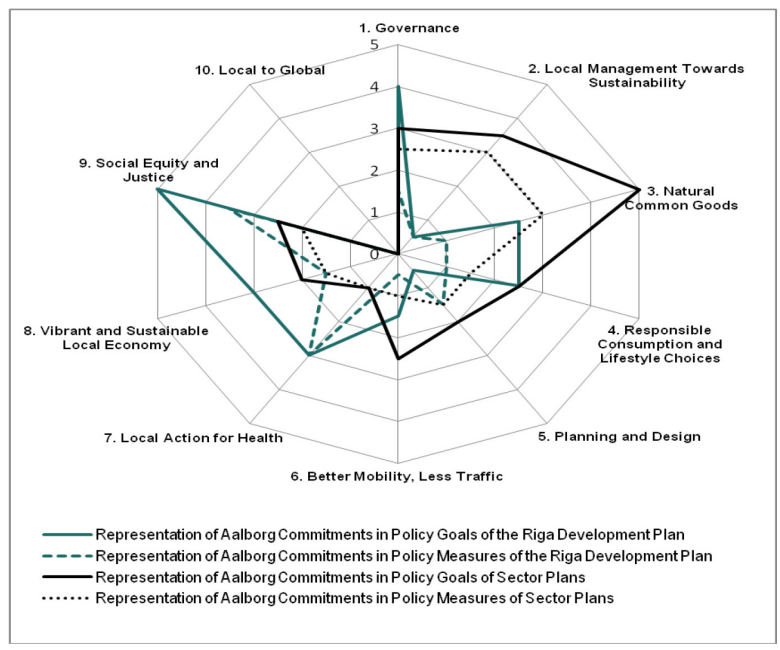

Figure 1: Representation of the Aalborg Commitments in the development plan of Riga. 


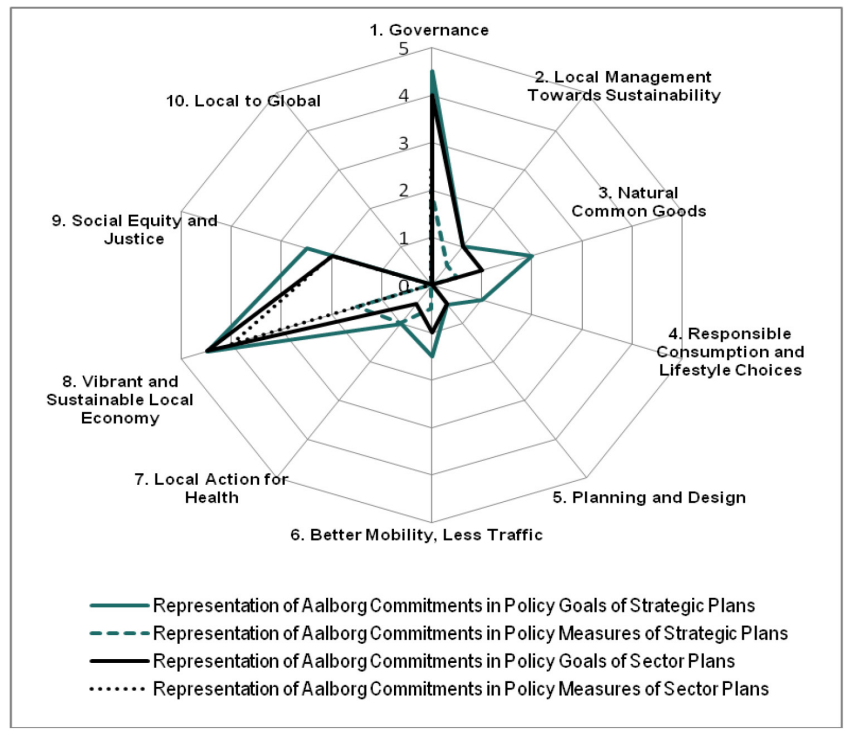

Figure 2: Representation of the Aalborg Commitments in development plans of Daugavpils.

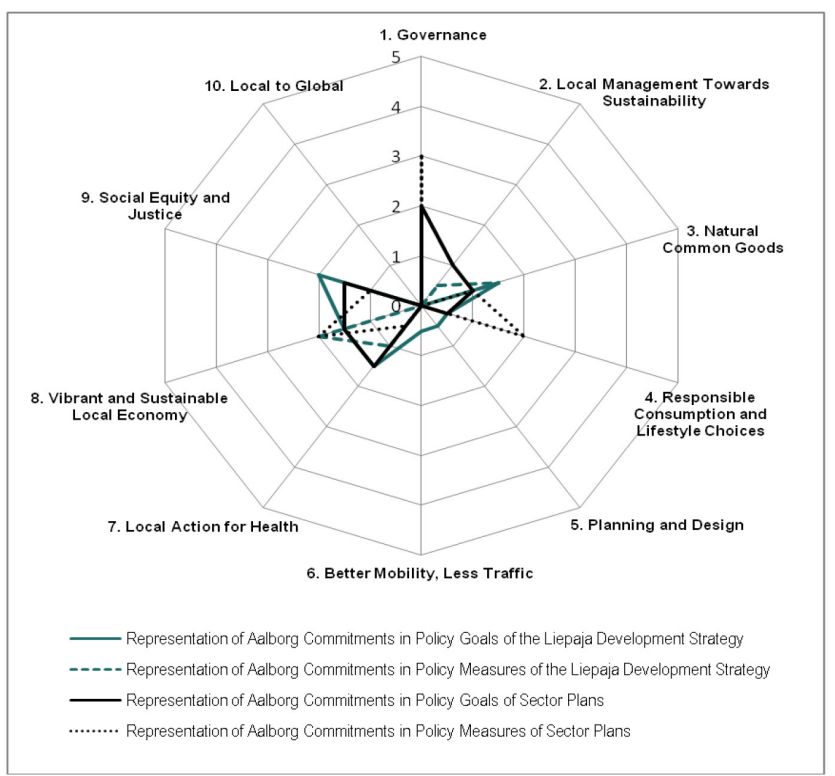

Figure 3: Representation of the Aalborg Commitments in the development plans of Liepaja. 
142 Ecosystems and Sustainable Development IX

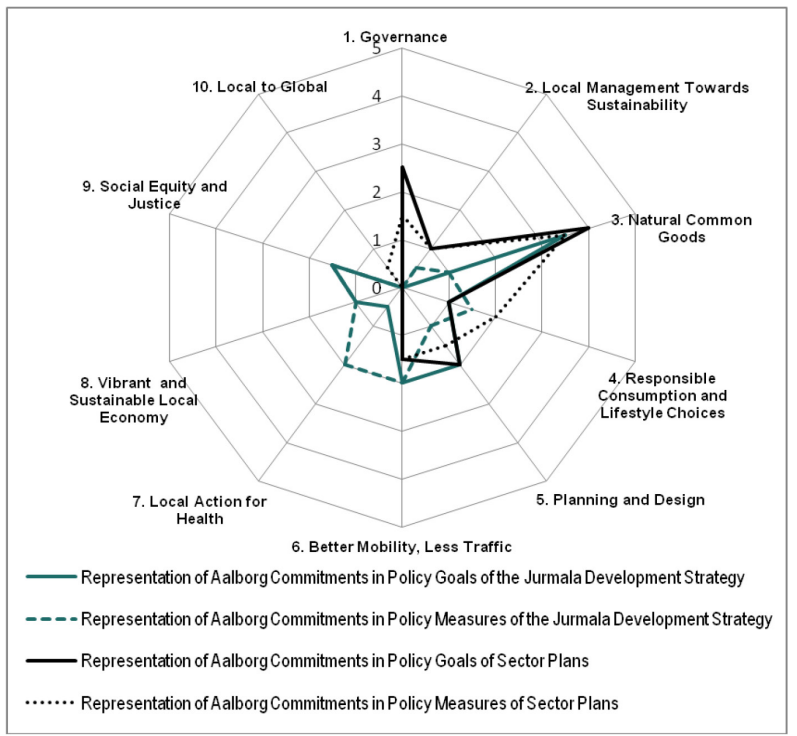

Figure 4: Representation of the Aalborg Commitments in development plans of Jurmala.

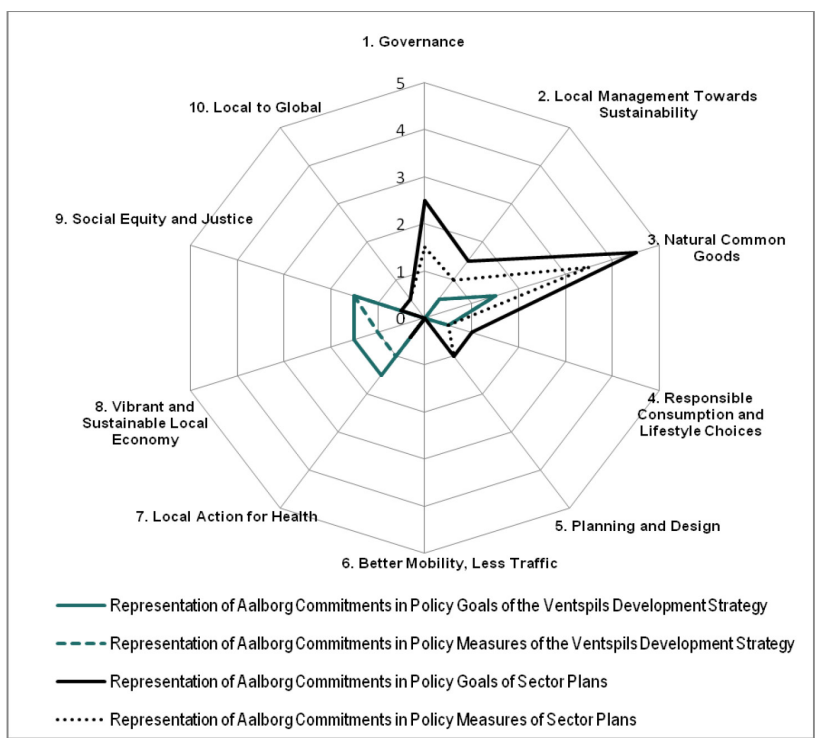

Figure 5: Representation of the Aalborg Commitments in development plans of Ventspils. 


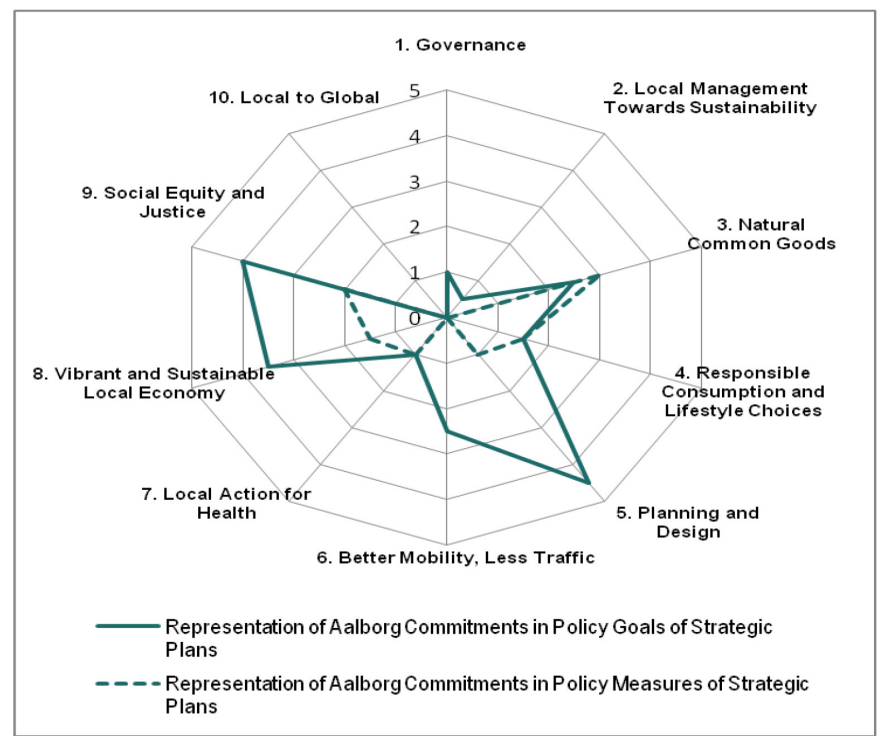

Figure 6: Representation of the Aalborg Commitments in development plans of Rezekne.

\subsection{Results of the assessment of indicators}

Only three of the cities (Riga, Liepaja, Ventspils) studied use indicators to characterize and monitor development trends. In Riga the European Common Indicators (ECI) [20] and Cities Environment Reports on the Internet - CEROI [21] are used to monitor, in part, the implementation of the Riga Development Plan. However, the ECI and CEROI together fully characterize only two Aalborg Commitments (in Aalborg Commitment groups 5 - Planning and Design and 6 - Better Mobility, Less Traffic), but partially characterize 22. Appropriate indicators do not exist for 26 of the Aalborg Commitments. Consequently, only partial monitoring of the implementation of sustainability can be undertaken using the CEROI and ECI indicators. Furthermore, available indicators indicate predominantly unsustainable trends. Additionally, as the CEROI and ECI indicators are not directly linked to the development goals of the city, as defined in sector plans and the Riga Development Plan, they do not fullfil a reporting or monitoring function for the goals defined therein.

The indicators used by Liepaja (Long-Term Development Strategy Monitoring System Indicators) fully characterize only three Aalborg Commitments and partially characterize 12. However, for 35 of the Aalborg Commitments appropriate indicators do not exist. Consequently, sustainability of development in Liepaja can be partly or fully monitored in relation to only 15 of the Aalborg Commitment criteria. Not surprisingly the Long-Term Development Strategy Monitoring System Indicators show the highest coherence with Aalborg Commitment groups 3 - Natural Common Goods, 8 - Vibrant and Sustainable Local Economy and 9 - Social Equity and Justice for which goals and measures 
in the Long-Term Development Strategy also have the greatest coherence with the Aalborg Commitments. Time series data are not available for these indicators to monitor development trends.

The indicators used in Ventspils (Environmental Indicators) show only a weak coherence with Aalborg Commitment groups 3 - Natural Common Goods, 4 - Responsible Consumption and Lifestyle Choices and 5-Planning and Design. Consequently, they have limited value in monitoring sustainability even in the traditional environmental themes. Time series data are not available for these indicators to monitor development trends.

\subsection{Survey results - assessment of municipal institutional arrangements and governance practices}

The survey of institutional arrangements and governance practices of the municipal administrations points to a number of significant shortcomings in relation to good governance in general and, particularly, in relation to governance for sustainable development. The survey indicates that municipal personnel and decision makers have limited awareness and understanding regarding the relevance and role of sustainable development in urban planning and development. Knowledge is also lacking concerning the meaning of sustainable urban development with respect to specific urban problems and issues. Furthermore, in practice no institution is responsible for coordinating sustainable development policy formulation and implementation within the municipal administrations. Some issues associated with sustainable development are managed by municipal environmental departments, but these are largely related to the environmental dimension and are marginal to the mainstream of development planning and decision-making in the municipalities. Similarly, no planning documents in the cities serve the function of coordinating sustainable development policy implementation. Consequently, as the assessment of municipal planning documents indicates, development policies and measures lack coherence in relation to the Aalborg Commitments. Additionally, few permanent intersector cooperation mechanisms operate in the municipal administrations. As a result, the traditional sectoral approach to policy-making is reinforced which hinders the integration of sustainability issues and criteria into mainstream municipal development policies.

Cooperation between the municipal administrations and stakeholders presently is related to one time short-term events legislated by planning, construction and environmental impact assessment regulations - no permanent cooperation mechanisms exist. The limited scope of stakeholder participation does not foster openness, transparency and accountability in development planning and decision-making. Minimal skills and knowledge regarding participatory methods for stakeholder consultation amongst municipal administration personnel in part explains the limited opportunities for involvement of stakeholders in policy-making activities.

The municipal administrations do not use management tools and systems to organise and systematise the formulation, implementation and monitoring of sustainable development policy. Consequently, it is not entirely surprising that 
considerable discrepancies exist between municipal development policies and measures and the Aalborg Commitments and that sustainable development trends are poorly documented.

\section{Conclusions}

\subsection{Municipal planning documents and indicators}

The assessment revealed significant discrepencies between the sustainability criteria of the Aalborg Commitments and policy goals and measures defined in the municipal planning documents. Development policy goals provide cities with a weak orientation towards sustainability, whereas policy measures show limited coherence with policy goals and the Aalborg Commitments. Only Riga, Liepaja and Ventspils have a limited number of sustainability indicators that can be used in part to measure progress towards sustainable development. Based on the available indicators development is these cities is characterized by predominantly unsustainable trends. The cities investigated in this study do not use a systematic approach for planning, implementing and monitoring sustainable development. Future planning initiatives should ensure that plans define more clearly development goals that are linked to sustainability criteria, such as the Aalborg Commitments, and that implementation measures are coherent with defined development goals. Indicators that are direcly linked to plans goals should be developed concurently with plans to ensure monitoring of planning outcomes.

\subsection{Institutional arrangements and governance practices}

Present governance practices result in development policies and outcomes that are weakly supportive of sustainable development. To bolster governance for sustainable development in municipalities, existing institutional arrangements and practices could be strengthened and supplemented and capacity building undertaken, including: 1) organisation of training courses, seminars on sustainability issues; 2) provision of more information, publications, guidance materials on sustainable development issues; 3) provision of regular information on municipal development trends based on indicators; exchange visits to other municipalities to acquire 'good practice'.

In order to improve policy coordination and integration for sustainable development an institution empowered to coordinate sustainable development policy formulation and implementation could be established in municipalities. Political support for the coordinated implementation of sustainable development could be strengthened through the establishment of a new executive management structure at the level of municipal councils to steer sustainable development initiatives. Policy coordination and integration could be strengthened through the establishment of permanent intersectoral working groups for policy development and the evaluation of development proposals. Furthermore, inclusion of experts from stakeholder groups in intersectoral working groups would facilitate the 
development of policies that are better aligned with the needs of target groups or those impacted by development. Similarly, intergovernmental working groups could be established to address urban development issues that can only be addressed successfully through cooperation with neighbouring municipalities and other levels of government and planning jurisdictions.

To help design development policies that better reflects the needs of diverse stakeholders in the local community, consultative councils composed of stakeholder representatives could be established to input to the policy formulation and implementation process. Training provided to municipal administration personnel on participatory methods for stakeholder consultation would improve skills and knowledge and raise awareness about the need for and the potential benefits arising from broadening opportunities for stakeholder input in policy-making and decision-making.

Establishment of management systems or processes would help better organise and systematise the implementation of sustainable development. The Aalborg Commitment's model, that includes quantitative target-setting, monitoring of development trends with indicators, reporting on and evaluating progress, is one approach that can support sustainable development outcomes. Strengthening of governance practices would serve to improve the quality of sustainable development policy-making and decision-making and would foster the mainstreaming of sustainable development in municipalities in Latvia.

\section{References}

[1] World Commission on Environment and Development, 1987. Our Common Future, London, UK, Oxford University Press.

[2] MEPRD - Ministry of Environmental Protection and Regional Development, 2002. Latvian National Report "Rio +10 " to the World Summit on Sustainable Development in Johannesburg, Riga, 2002.

[3] Council of the European Union, 2006. Renewed EU Sustainable Development Strategy.

[4] COM 718 final, 2005. Communication from the Commission to the Council and the European Parliament on Thematic Strategy on the Urban Environment.

[5] European Commission, 2010. Europe 2020. A strategy for smart, sustainable and inclusive growth. http://ec.europa.eu/europe2020/ index en.htm

[6] Saeima of the Republic of Latvia, 2010. Sustainable Development Strategy of Latvia until 2030.

[7] LR likums, 2009. Development Planning System Law (in Latvian).

[8] LR likums, 2011. Territory Development Planning Law (in Latvian).

[9] UN,1993. Report of the United Nations Conference on Environment and Development, Rio de Janeiro, 3.-14. June 1992, Vol. 1: Resolutions Adopted by the Conference; Vol. 2: Documents adopted by the Conference, United Nations, New York. 
[10] Phahl, S., 2005. Institutional Sustainability, Int. J. Sustainable Development, Vol. 8, Nos. 1/2, pp. 80-96.

[11] UNCSD, 1996. Indicators of Sustainable Development, Framework and Methodologies, United Nations, New York.

[12] Meadowcroft, J. and Farrell, K.N. and Spangenburg, J., 2005. Developing a Framework for Sustainability Governance in the European Union, Int. J. Sustainable Development, Vol. 8, Nos. 1/2, pp. 3-11.

[13] Munda, G., 1995. Multicriteria Evaluation in a Fuzzy Environment, Physica Verlag, Heidelberg.

[14] Spangenberg, J.H., 2002. Environmental Space and the prism of sustainability: frameworks for indicators measuring sustainable development, Ecological Indicators, Vol. 57, pp. 1-14.

[15] Spangenberg, J.H., 2001. Investing in Sustainable Development, The Reproduction of Man Made, Human, Natural and Social Capital, Int. J. Sustainable Development, Vol. 4, No. 2, pp. 184-201.

[16] ICLEI - International Council for Local Environmental Initiatives, 1994. Charter of European Cities and Towns Towards Sustainability. ICLEI European Conference on Sustainable Cities and Towns, Aalborg, Denmark, 24-27 May 1994.

[17] ICLEI - International Council for Local Environmental Initiatives, 2004. Aalborg Commitments, http://www.aalborgplus10.dk/

[18] Zilans, A. and Abolina, K., 2009. A methodology for assessing urban sustainability: Aalborg commitments baseline review for Riga, Latvia, Environment, Development and Sustainability, Vol. 11, No. 1, pp. 85-114.

[19] Jonusa, L., 2008. Cēsu pilsētas ilgtspējības novērtējums. Maǵistra darbs Latvijas Universitātes Ģeogrāfijas un Zemes zinātṇu fakultātē, vides zinātnes nozarē (MSc thesis in Latvian).

[20] Riga City Council Riga Environment Centre Agenda 21 and University of Latvia, 2005. Sustainability of Development in Riga: Opportunities and Challenges, Riga City Council, Riga City Environment Centre Agenda 21 and University of Latvia, Faculty of Geography and Earth Sciences, 67 p. (in Latvian).

[21] Riga Environment Centre Agenda 21, 2005. State of the Environment in Riga (CEROI).http://www.ceroi.net/reports/riga/latviski/lvl index.htm 